Abstract

\title{
Assessment of Potential Supply of Ecosystem Services in Coimbra Municipality +
}

\author{
Inês Amorim Leitão *, Carla Sofia Santos Ferreira and António José Dinis Ferreira \\ Research Centre for Natural Resources, Environment and Society (CERNAS), Polytechnic Institute of \\ Coimbra, Coimbra School of Agriculture, Bencanta, 3045-159 Coimbra, Portugal; cferreira@esac.pt (C.S.S.F.); \\ aferreira@esac.pt (A.J.D.F.) \\ * Correspondence: ines.leitao@esac.pt \\ + Presented at TERRAenVISION 2019, Barcelona, Spain, 2-7 September 2019.
}

Published: 19 December 2019

\begin{abstract}
Land-use changes driven by human activities affect natural systems. Urbanization, forest monoculture and intensive agriculture are changing the functioning of many biotic and abiotic processes. This tends to decrease the ability of ecosystems to provide services, which leads to several problems particularly in cities. This study investigates the ability of urban areas with great population and environmental pressures, to supply ecosystem services. The study was carried out in Coimbra municipality, through the assessment of regulation, provisioning and cultural services. The quantification of ecosystem services was based on the evaluation performed by experts familiar with the study area, through questionnaires. A total of 31 questionnaires were completed. The experts ranked the potential supply of 30 ecosystem services for the 33 existent land-uses. based on a qualitative evaluation: "strong adverse potential", "weak adverse potential", "not relevant", "low positive potential" and "strong positive potential". The qualitative evaluation was converted into a quantitative classification $(-2,-1,0,1,2)$. The values were used to develop an ecosystem services quantification matrix and to map the information in the study area, using Geographic Information Systems (GIS). Despite the limited ecosystem services provided by urban areas, agricultural fields and especially green spaces are relevant for the provision of resources essential for human survival and well-being. The methodology used in this work is still useful for the quantification of ecosystem services in cities with characteristics associated with the Mediterranean climate. This type of studies are important to (i) anticipate problems originated from the loss of ecosystem services, (ii) identify good and bad practices of land use changes, (iii) the role of connectivity in maintaining biotic and abiotic processes, and (iv) develop practices that promote the sustainable development of societies.
\end{abstract}

Keywords: ecosystem services; urbanization; green areas; sustainability

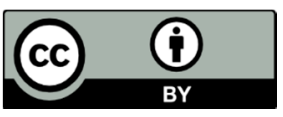

(C) 2019 by the authors. Licensee MDPI, Basel, Switzerland. This article is an open access article distributed under the terms and conditions of the Creative Commons Attribution (CC BY) license (http://creativecommons.org/licenses/by/4.0/). 